\title{
Caffeine and Pressure Flow Autoregulation
}

\author{
Gary F. Merrill*, Denisa M. Costea, Victoria A. Sharp
}

Department of Cell Biology and Neuroscience, Division of Life Sciences, School of Arts and Sciences, Rutgers University, Nelson Biological Laboratories, Piscataway, NJ, USA

Email: *merrill@dls.rutgers.edu

How to cite this paper: Merrill, G.F., Costea, D.M. and Sharp, V.A. (2019) Caffeine and Pressure Flow Autoregulation. World Journal of Cardiovascular Diseases, 9 , 253-266.

https://doi.org/10.4236/wjcd.2019.94023

Received: January 16, 2019

Accepted: April 16, 2019

Published: April 19, 2019

Copyright $\odot 2019$ by author(s) and Scientific Research Publishing Inc. This work is licensed under the Creative Commons Attribution International License (CC BY 4.0).

http://creativecommons.org/licenses/by/4.0/ cc) (i) Open Access

\begin{abstract}
The benefits or detriments of caffeine on the human cardiovascular system have not been thoroughly studied and are still poorly understood. In a world where caffeinated beverages are evidently the adult drug of choice (e.g. coffee, energy drinks, soda, tea), investigating its effects on our bodies is of great importance. In this study, we examined the effects of caffeine, taken as a tablet, on pressure-flow autoregulation. Young adults between 18 and 21 years of age were the experimental subjects. They were instrumented to monitor systemic arterial blood pressure, peripheral blood flow, calculated peripheral vascular resistance, and the electrocardiogram during an autoregulatory maneuver in the absence and presence of caffeine. Caffeine-mediated vasoconstriction was observed as early as 15 minutes after its consumption. Sixty minutes post-caffeine, vasoconstriction was so prominent that autoregulation was abolished. This was reflected, in part, as a significant reduction in blood flow that accompanied a 3 -fold increase in calculated peripheral resistance and a significant increase in systemic arterial pressure. Heart rate was unaffected by caffeine under our experimental conditions. We conclude that caffeine has the ability to inhibit significant cardiovascular properties including pressure-flow autoregulation. Even though more work is needed, the significant caffeine-mediated changes in flow, pressure and resistance during autoregulation could have serious consequences for the cardiovascular system specifically, and for one's overall health in general.
\end{abstract}

\section{Keywords}

Cardiovascular, Flow Regulation, Local Blood Flow, Mammalian

\section{Introduction}

Caffeine is widely used for non-medical and medical purposes. It has various benefits such as respiratory stimulation in premature infants with sleep apnea [1] [2]. 
However, it is most frequently consumed in beverages or as over-the-counter capsules, pills and tablets to boost one's energy [3]-[8]. Thus, abuse of caffeine has become a habit for many people even though there are unanswered questions about its effects on the body, especially the brain and cardiovascular system. Since caffeine is an adenosine receptor antagonist, adenosine-mediated circulatory regulation in the brain, heart, and elsewhere can be impaired by caffeine [9] [10] [11] [12].

Although caffeine stimulates the central nervous system and can increase alertness there might be negative consequences that outweigh these effects. For example, we have recently reported that caffeinated hot coffee has dual, aphysiological cardiovascular effects [13]. As a single bolus (swallow) of hot coffee passes through the esophagus it disturbs stability of the ECG, causing a wandering isoelectric line. Also, while hot coffee is stored in the stomach, thus significantly elevating gastric/body temperature, pronounced thermoregulatory peripheral vasodilation occurs (an attempt to eliminate excess stored heat). Peripheral vasodilation is followed by significant vasoconstriction, increased peripheral vascular resistance, and a marked reduction in blood flow [13].

In the current experiment, we focused on the influence of caffeine on pressure-flow autoregulation. Results are consistent with our previous report [13] and demonstrate the need for much more work.

\section{Methods}

\subsection{Subjects}

Experimental subjects $(n=18)$ were college-age young adults enrolled in courses at Rutgers University. They were male $(n=9)$ and female $(n=9)$ ages $20 \pm 1$ years of age and of multiple ethnicities (White, Black, Asian, Indian, other). Only two exclusions were considered: those currently taking medications for cardiovascular disease (none), and those having consumed caffeine less than 24 hours before investigation (none). Because this exercise was an integral part of the pedagogy of these courses it was exempt from IRB review and approval. Moreover, the activity was discussed in detail in class (e.g. experimental design, all subjects required to participate) and no identifying records were maintained or stored, therefore subjects were also exempt from providing informed consent.

Subjects were male and female from several cultural/ethnic backgrounds. They were either regular (daily) or irregular (weekly or less frequent) users of caffeinated beverages. All arrived at the laboratory having avoided caffeinated beverages for at least $24-48$ hours.

\subsection{Experimental Design}

Instrumentation-After subjects arrived at the laboratory they rested comfortably on a hospital examination bed in the supine position. Room temperature was maintained at $22^{\circ} \mathrm{C}-24^{\circ} \mathrm{C}$, and four physiological transducers were attached to each subject. These included a sphygmomanometer blood pressure cuff (Adult 
size, Index) with a built in pressure sensor (strain gauge balance). The cuff and pressure sensor were connected to a wall-mounted Baumanometer (model CE1562). A cardio microphone (model MLT201, AD Instruments, Colorado Springs, $\mathrm{CO}$ ) was placed over the left brachial artery (near the antecubital fossa) and secured in place with Transpore, hypoallergenic surgical tape (3 M Health Care, St. Paul, MN) and Tegaderm Film (3 M Health Care, Neuss, Germany). A pulse plethysmograph (model TN1012/ST, ADInstruments) was attached to the left index or middle finger (whichever presented the greater surface area) and snuggly secured with a Velcro strap. Heart rate was determined from a standard limb lead electrocardiogram (LLI, ECG).

Data acquisition system-All four transducers were attached to a Power Lab data acquisition system (model 8/35, AD Instruments) coupled to a desktop computer (HP Compaq LA2006x) running LabChart software (v. 8.1.12., September, 2018). All waveforms could be periodically or continuously displayed on a computer monitor for investigator observation.

Experimental protocol-Following instrumentation a timer was set, lights were dimmed, and a 15-minute period was allowed for monitored variables to achieve physiological steady state conditions. After 15 minutes steady state, baseline data were collected including: recordings of heart rate (HR, cycles per minute, cpm), ECG, systemic mean arterial blood pressure ( $\mathrm{Pa}, \mathrm{mmHg})$, and volume in the index finger ( $\mu$ l per pulse). Multiplying pulsatile changes of volume of the index finger by heart rate yielded an estimate of finger blood flow $(\mu \mathrm{l} / \mathrm{min})$. Vascular resistance to blood flow in the instrumented finger could then be estimated by dividing mean arterial blood pressure by blood flow $(\mathrm{mmHg} / \mu \mathrm{l} / \mathrm{min})$.

Subsequently, and on cue, the subject raised their fully-extended arms above the chest (heart) for five minutes. During this maneuver estimates of blood flow, blood pressure and resistance to blood flow were made (or calculated) at 45 - 60 seconds (before autoregulation) and again at 4 - 5 minutes (during autoregulation). On cue the subjects then lowered their arms to the pre-elevated resting position. Data collected during this pre-caffeine period were designated "baseline".

After baseline data were collected each subject consumed $400 \mathrm{mg}$ of caffeine (two tablets of $200 \mathrm{mg}$ caffeine each, NODOZ Alertness Aid, GSK Consumer Healthcare, Warren, NJ). The timer was reset for 60 minutes, and the subjects were asked to rest quietly with as little movement as possible. Hemodynamic variables were monitored by the data acquisition/computer system continuously. However, at 15-minute intervals we estimated blood pressure by inflating/deflating the pressure cuff $(20-30 \mathrm{sec})$. Restoring finger blood flow (post-occlusion of the compressed brachial artery) and monitoring pulsatile arterial sounds (cardio microphone) could be used to estimate pulsatile and mean arterial blood pressures at these 15-minute timed intervals.

At 60 minutes post-caffeine the autoregulation maneuver described above was again completed. Data collected during this period were considered "experi- 
mental" and were later compared, statistically, with the pre-caffeine data.

Statistics-The experiment was designed a priori and is a follow up to a related experiment conducted in our laboratory in the past year [13]. Initial variability was identified using Analysis of Variance for Repeated Measures (one-way ANOVA). Means were compared using Students t-test. All data are presented as means plus or minus one standard error of the mean (s.e.m.). Statistically significant differences were established at $\mathrm{P}<0.05$.

\section{Results}

Examples of an entire experiment can be reviewed in Figure 1. The horizontal timelines have been compressed markedly to fit the $75+$ minute experiment on a single page.

Heart rate-After fifteen minutes steady state baseline heart rate was $76 \pm 2$ cycles per minute. Heart rate did not change significantly during autoregulation before or after caffeine (e.g. $74 \pm 2$ vs $71 \pm 2$ cycles per minute 60 minutes after caffeine) (Figure 2).

Systemic mean arterial blood pressure was $79 \pm 4 \mathrm{mmHg}$ under baseline conditions. Five minutes after raising arms pressure fell significantly to $52 \pm 3$ and $61 \pm 4 \mathrm{mmHg}$ in the absence and presence of caffeine, respectively (Figure 3). Both means were significantly reduced compared to baseline, and $61 \pm 4 \mathrm{mmHg}$ 60 minutes after caffeine was significantly greater than $52 \pm 3 \mathrm{mmHg}$ before

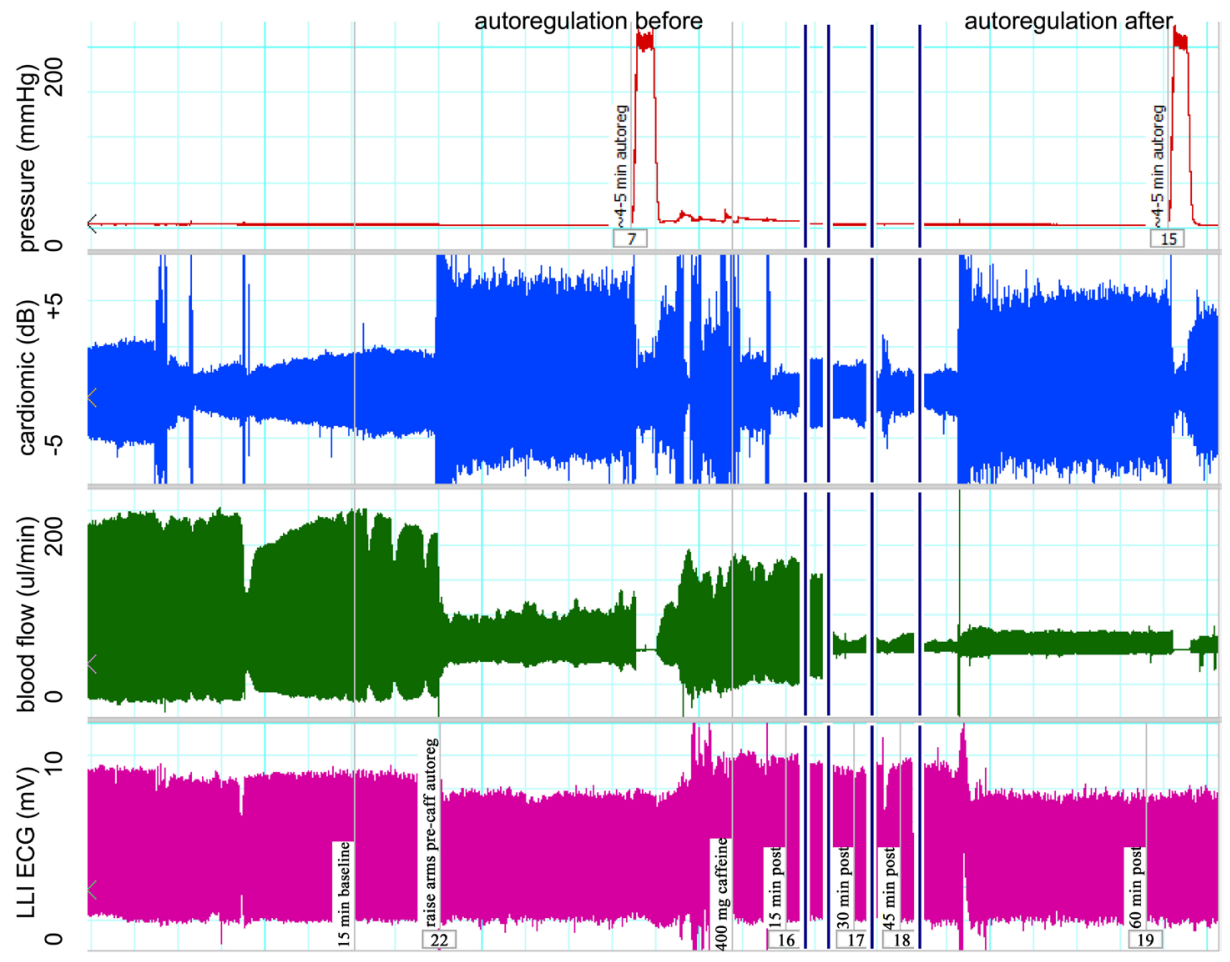

Figure 1. Representative tracing of a compressed complete experiment with the pressure channel (channel 1). Note the marked and significant reduction in finger blood flow in the presence of caffeine (autoregulation after). Compare details, especially in plethysmography (channel 3) before and after caffeine. 


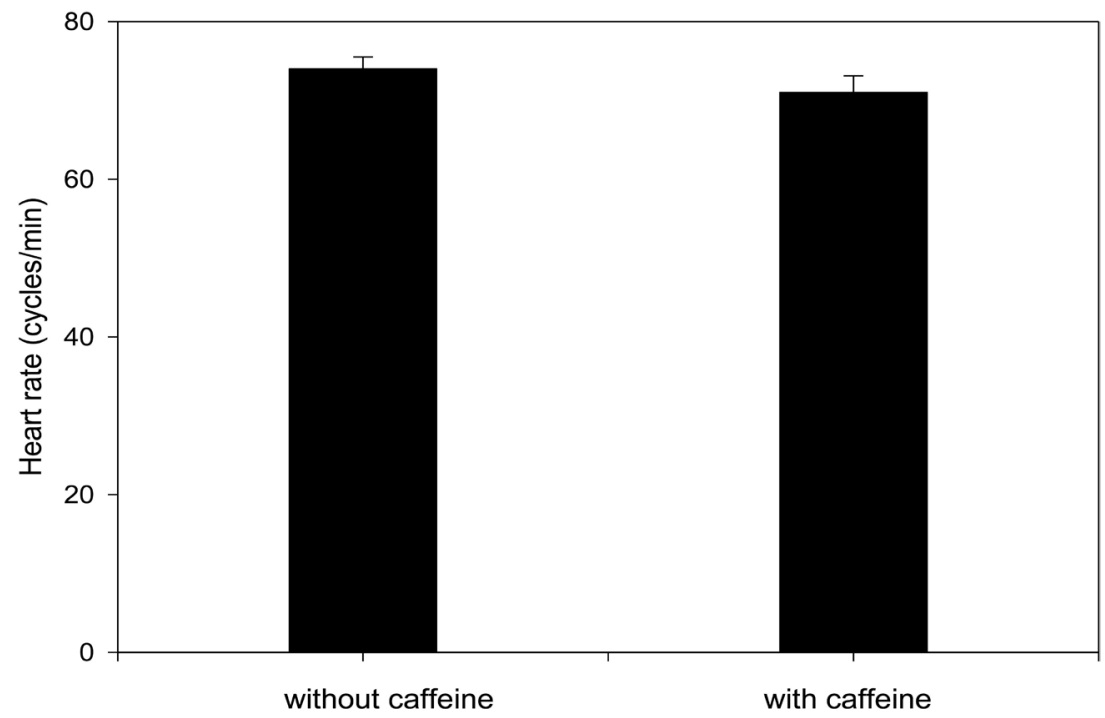

Figure 2. Heart rate. Note the absence of statistically significant differences in the absence and presence of caffeine. This is noteworthy because the literature reports caffeine-mediated increments and decrements in heart rate.

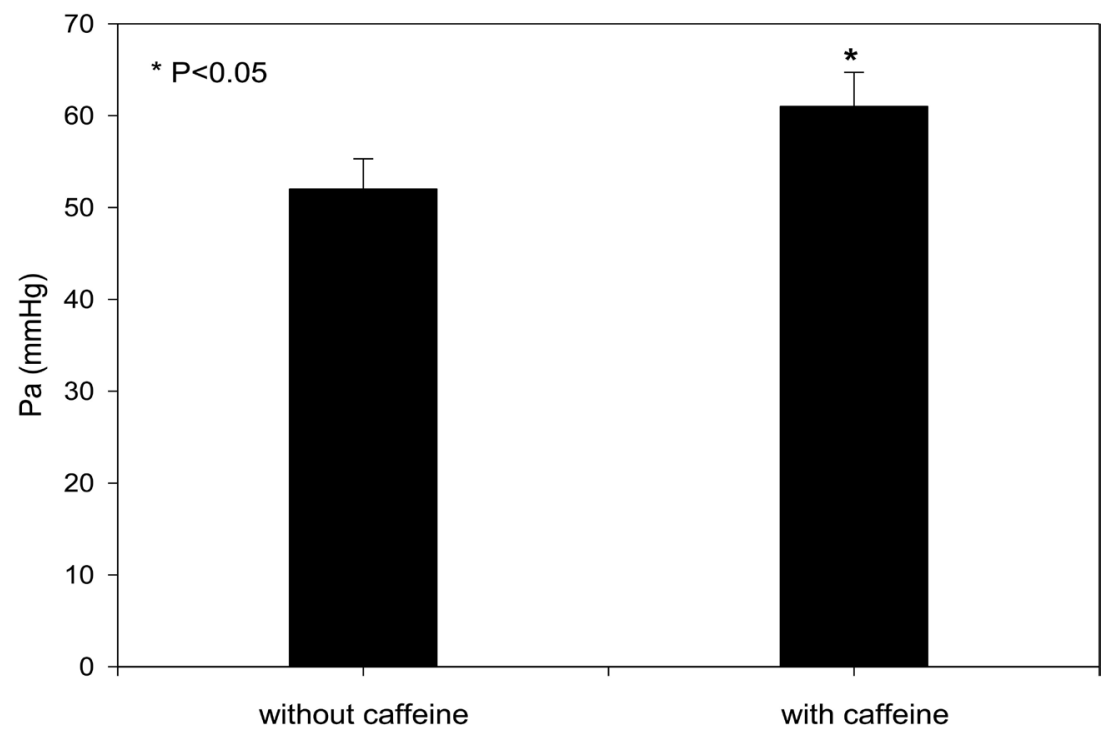

Figure 3. Systemic mean arterial blood pressure in the absence and presence of caffeine. Note the statistically significant elevation of blood pressure in the presence of caffeine.

caffeine $(\mathrm{P}<0.05)$.

Pulsatile volume in the instrumented finger was $88 \pm 15 \mu$ l under baseline, steady state conditions (Figure 4). This did not change significantly in the absence of caffeine after 4 - 5 minutes of raising one's arm above the heart. Conversely, in the presence of caffeine, pulsatile volume during arm raising fell markedly and significantly to $29 \pm 4.3 \mu \mathrm{l}$ after $4-5$ minutes, i.e. there was no evidence of flow autoregulation.

Peripheral vascular resistance under baseline conditions was $1.3 \pm 0.2$ $\mathrm{mmHg} / \mu \mathrm{l} / \mathrm{min}$ (Figure 5). This remained unchanged at $1.0 \pm 0.1$ in the absence of caffeine but rose significantly to $2.8 \pm 0.4 \mathrm{mmHg} / \mu \mathrm{l} / \mathrm{min} 60$ minutes after 


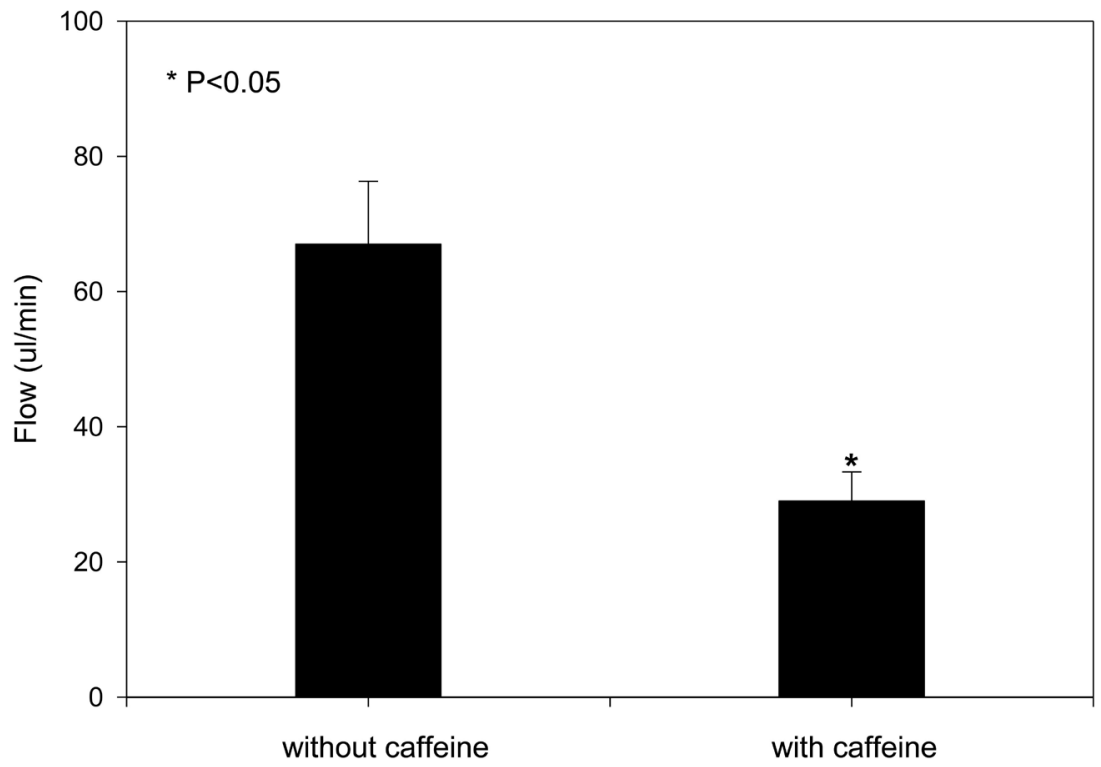

Figure 4. Finger volume in the absence and presence of caffeine. Note the statistically significant decrease in volume in the presence of caffeine. The hypo-perfusion is consistent with caffeine-mediated elevation of peripheral vascular resistance (see Figure 5).

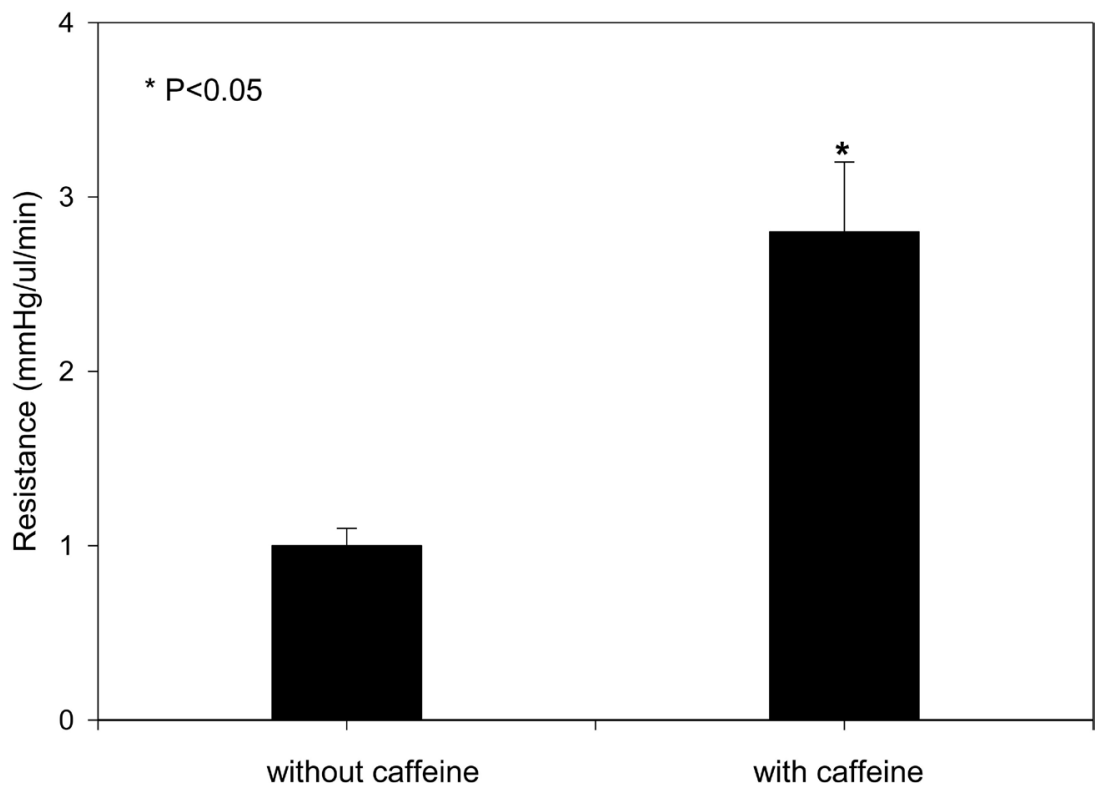

Figure 5. Resistance to blood flow in the absence and presence of caffeine. Note the marked and statistically significant elevation in resistance in the presence of caffeine. The increase in resistance, coupled with a reduction in flow, explains the increase in systemic mean arterial blood pressure caused by caffeine.

caffeine $(\mathrm{P}<0.05)$. All hemodynamics are summarized graphically in Figure 6. Also, autoregulatory responses are summarized in Table 1.

While the standard limb lead ECG was used primarily to measure heart rate, we did not notice acute effects of caffeine on waveforms, intervals and segments. For example, we did not see caffeine-induced ST-segment changes. Nor were ventricular premature beats (VPB), ventricular salvos (VS) or ventricular bigeminy 


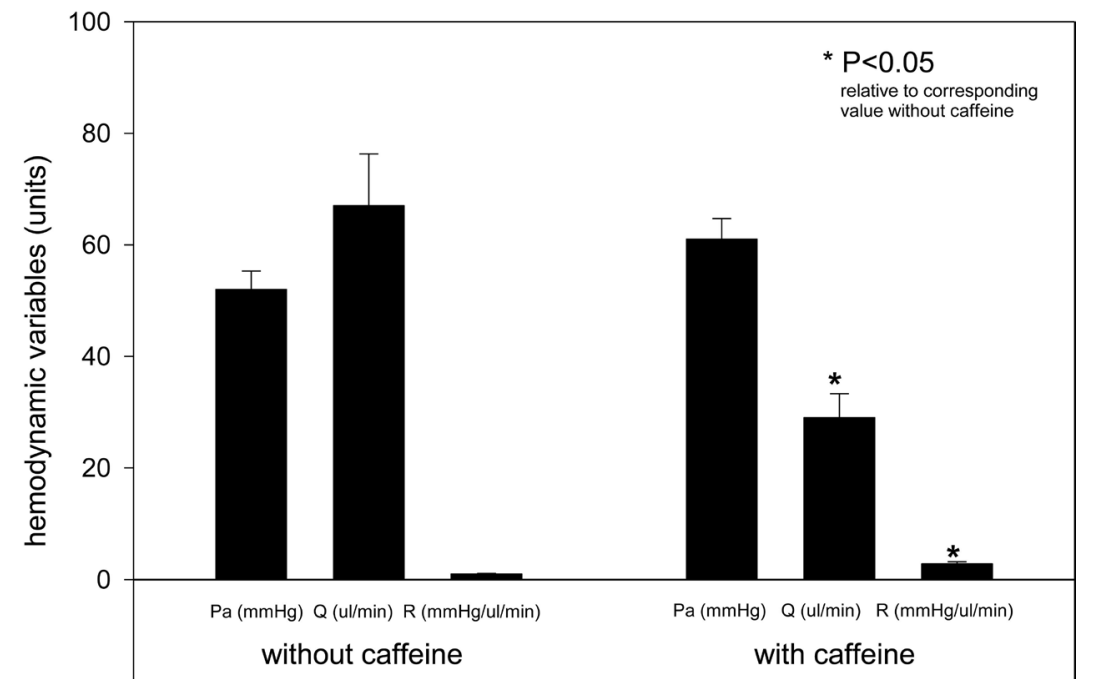

Figure 6. This is a composite illustration of Figures 3-5. Comparing all three hemodynamic variables that contribute to pressure-flow autoregulation, in the absence and presence of caffeine, presents a more complete picture of the experimental outcome.

Table 1. Cardiovascular variables before (baseline, pre-caffeine) and sixty minutes after consuming caffeine.

\begin{tabular}{ccc}
\hline & \multicolumn{2}{c}{ Autoregulation } \\
\cline { 2 - 3 } baseline & pre-caffeine & post-caffeine \\
\hline $\mathrm{HR}(\mathrm{cpm})$ & $74 \pm 2$ & $71 \pm 2$ \\
$76 \pm 2$ & & \\
$\mathrm{~Pa}(\mathrm{mmHg})$ & $52 \pm 3$ & $61 \pm 4^{*}$ \\
$79 \pm 4$ & & $29 \pm 4^{*}$ \\
Flow $(\mu \mathrm{l} / \mathrm{min})$ & $67 \pm 9$ & \\
$88 \pm 15$ & $1.0 \pm 0.1$ & $2.8 \pm 0.4^{*}$ \\
$\mathrm{R}(\mathrm{mmHg} / \mu \mathrm{l} / \mathrm{min})$ & & \\
$1.3 \pm 0.2$ & &
\end{tabular}

$\mathrm{HR}$, heart rate; cpm; cycles per minute; Pa, systemic mean arterial blood pressure; $\mu$ l, microliters; R, resistance to blood flow. ${ }^{\star} \mathrm{P}<0.05$ when compared with corresponding pre-caffeine value.

(VB) evident with or without caffeine.

Subjective, non-quantifiable responses-Fifteen to thirty minutes post-caffeine several subjects reported feeling anxious and alert. From 30 - 60 minutes post-caffeine other subjects expressed having cold and/or tingling fingers and toes. Yet others had sweaty palms. Of these, a few mentioned sensations of numbness and "needles and pins". Others felt muscle tremors in the chest wall and upper extremities. One or two subjects experienced tightening of the chest and more vigorous heart beats, as well as mild headache 30 - 60 minutes post-caffeine.

\section{Discussion}

1) Cerebral and cardiac effects of caffeine

Caffeine, like alcohol and tobacco, is legally used but unlike alcohol and tobacco its sale in the form of powders and tablets containing high concentrations of caffeine and unknown contents is not controlled or restricted. Deaths from 
consumption of over-the-counter and dietary caffeine products remain a concern and should be given higher regulatory priority and oversight. Extreme frequency of use and uncontrolled sales of caffeinated products, coupled with adverse cerebral and cardiovascular actions of the drug, pose a serious risk to the health and safety of consumers.

For example, a 20-year-old woman presented at a local hospital with severe agitation, tremor, and vomiting less than two hours after suicidal ingestion of concentrated caffeine (powder and tablets). Within minutes of arrival she experienced ventricular fibrillation. Defibrillation, intubation, and amiodarone administration temporarily resuscitated her but she subsequently experienced twenty three more episodes of pulseless ventricular fibrillation/tachycardia, each responsive to defibrillation. With additional treatment, including several weeks in a psychiatric unit, this patient made a full recovery. Her circulating plasma caffeine concentrations six and eighteen hours after ingestion were 240 and 150 $\mu \mathrm{g} / \mathrm{ml}$ [14] (note: 80 - $100 \mu \mathrm{g} / \mathrm{ml}$ caffeine can be fatal (see refs [15] [16] [17])).

A young man age sixteen collapsed at a high school in April, 2017, in South Carolina after consuming a McDonald's latte, a large Mountain Dew, and an energy drink in less than two hours. This 16-year-old died from a "caffeine-induced cardiac event causing a probable arrhythmia" the coroner said. He had no pre-existing heart condition (Reuters News Agency, April, 2017). These two reports, coupled with statistics published in recent reviews [15] [16] [17], provide convincing evidence that caffeine can be lethal.

Cerebral vasoconstrictor effects of caffeine have been established for more than eighty years [18]-[23]. Between 1935 and 2017 investigators reported a reduction in cerebral blood flow caused by intravenous and/or oral administration of caffeine. Mathew saw these effects as early as thirty minutes after oral administration of 250 or $500 \mathrm{mg}$ caffeine [22], and responses to the two doses were not significantly different. More recently Merola, using functional MRI (fMRI), observed significant effects of caffeine on the cerebral extraction of oxygen $(16 \%$ increase), cerebral blood flow (30\% decrease) and cerebral oxygen consumption 19\% (decrease) [24]. Thus, caffeine has powerful cardiovascular and cerebrovascular effects in otherwise healthy young adults.

We did not measure indices of oxygen consumption in our investigation. However, peripheral blood flow did decrease markedly and was evident as early as 15 - 30 minutes post-administration of an oral dose of $400 \mathrm{mg}$ caffeine. It is not unreasonable, therefore, to speculate that oxygen metabolism would have also been affected.

2) Caffeine and autoregulation of blood flow

Our motivation to investigate caffeine began a few years ago when we tried to design an experiment using students enrolled in a seminar course. We planned to divide the class in two, those who did and others who did not consume caffeinated beverages [13]. Finding young adults on or off university campuses who do not consume caffeinated beverages has proven to be a virtual impossibility.

By standards of classic experimental physiology autoregulation of blood flow 
is defined as the ability of an organ/tissue to maintain a relatively constant blood supply over a wide range of systemic arterial blood pressures [25] [26] [27] [28] [29]. The typical approach to investigating this phenomenon in an experimental animal laboratory is to instrument an organ (e.g. kidney, heart, skeletal muscle) so its blood supply can be measured during and shortly after adjustments in arterial blood pressure [25]. In the current experiment we instrumented conscious young adults so peripheral blood flow to a digit, and the arterial driving pressure needed to perfuse the digit, could be estimated. After a 15-minute baseline period, which included measurements of blood flow and blood pressure, we asked the supine subjects to fully extend their arms and hands above the heart for five minutes.

By changes in gravitational and hydrostatic forces, this procedure initially reduced blood pressure and blood flow to the instrumented finger (first 30 - 60 seconds). In the absence of caffeine, and by a combination of metabolic, myogenic, and neurogenic mechanisms, blood flow to the finger was partially restored over the next 4 - 5 minutes even though blood pressure was still significantly reduced (e.g. $52 \pm 3$ vs $79 \pm 4 \mathrm{mmHg}, \mathrm{P}<0.05$ ). Sixty minutes after consuming 400 mg of caffeine, and in the same subjects, blood flow was less than half its pre-caffeine value when the same arm-raising procedure was repeated. That is, no evidence of pressure-flow autoregulation was seen in the presence of caffeine.

At the same time blood pressure was modestly but significantly elevated when compared to corresponding values in the absence of caffeine. Calculated peripheral vascular resistance in the instrumented finger had increased by almost 3 -fold above the pre-caffeine level. This was not surprising. Within 15 minutes of consuming caffeine, blood flow to the instrumented finger began to decrease. The steady decline in blood flow continued until reaching its nadir about 45 - 60 minutes after caffeine. That is, caffeine produced rapid and sustained peripheral vasoconstriction.

3) Caffeine and adenosine

Adenosine is a ubiquitous physiological regulator of organ and tissue blood flow [28] [30] [31] [32] [33] [34]. Adenosine's vasodilator properties were first reported by Robert Berne et al. in the early 1960s [34]. Later, Ray Olsson et al. were among the first to begin work on identifying cardiac/vascular adenosine receptors [35] [36] [37] [38]. Since those initial discoveries many review articles about adenosine's physiological properties and signal transduction pathways have been published [39] [40]. Adenosine is an important local tissue regulator of both coronary and cerebral blood flow [30] [31] [32] [33] [34]. It is also an important nucleoside in the regulation of blood flow in tissues as disparate as skeletal muscle and gut. It occurs naturally in our bodies and is produced at all times, more so during periods of hypoxia and ischemia [30] [31] [32] [33] [34].

Caffeine (1, 3, 7-trimethylxanthine) is one of several methyl xanthines that recognizes and binds to adenosine receptors in a pharmacologically competitive manner [41] [42] [43]. Caffeine is commonly-consumed by Americans, old and young, including pregnant women [44]. Administration of caffeine to pregnant 
rats not only affects the dam but also affects the fetuses; maternal and fetal plasma concentrations of caffeine are indicative of equal exposure to the drug [45]. Fetal ECGs exhibit more extensive caffeine-mediated changes than are seen in the dams' ECGs. The frequency of ectopic beats and abnormal $\mathrm{T}$ waves are directly related to plasma concentrations of caffeine in the fetus [45].

Moreover, in humans, maternal consumption of caffeine during early days/weeks of pregnancy reduces birth weight and size of offspring. Under such conditions caffeine also has lasting detrimental effects on heart and cardiovascular function [40]. For example, caffeine impairs ubiquitous signaling properties of adenosine in the fetal heart (e.g. disruption of DNA methylation), and these pathophysiological, epigenetic effects can last well beyond the exposed generation [40]. The developing fetal heart lacks the enzymes needed to metabolize and detoxify methylated products [40]. Thus, the interactions between caffeine (and analogs like theobromine, theophylline, aminophylline and others) and adenosine need to be more thoroughly investigated by physiologists and pharmacologists. This is especially true given the volume of people who consume caffeinated products and the importance of the cerebral and coronary vasculature, as well as other circulatory beds in the human body.

\section{Summary and Conclusions}

Since the distal segments of human fingers contain skeletal muscle one would expect them to display some degree of autoregulation. In the current study mean arterial pressure in fingers of the initially-elevated arms dropped significantly below baseline values. So did flow. However, during the next four to five minutes and in the absence of caffeine, flow returned to levels that were not significantly different from baseline values, i.e. the finger autoregulated blood flow. Conversely, after 60 minutes of caffeine the finger did not autoregulate its blood supply.

By some reports, $50-60 \mathrm{mmHg}$ is the lower end of the autoregulation range [25]. Therefore, one might not have expected flow to be fully restored at these arterial pressures. However, in our experience in healthy young adults, blood pressure is well below the standard $120 / 80 \mathrm{mmHg}$. Therefore, one might also expect the autoregulatory range to be modified in healthy young adults. That remains to be investigated. Still, caffeine's marked vasoconstrictor properties and accompanying significant increment in calculated peripheral vascular resistance prevented autoregulation in the human finger.

\section{Limitations}

Despite the above conclusions, there are limitations to this investigation. For instance, we examined only one elevation in pressure. In an experimental animal laboratory, at least two or three elevations and two or three reductions in pressure would have been investigated. Secondly, we did not measure finger blood flow directly (e.g. ultrasonically, electromagnetically). We calculated blood flow 
by multiplying plethysmographic changes in finger volume during single cardiac cycles by heart rate, thereby indirectly estimating blood flow. Thirdly, we did not take into consideration the potential variability in caffeine tolerance among subjects. Ideally we would have divided subjects into those who do and do not consume caffeinated beverages. Finding nonconsumers of caffeinated beverages on university campuses, as already mentioned, is difficult.

Regardless of these and other limitations the results are clear and unambiguous. In the presence of caffeine, vasculatures in the finger were unable to autoregulate their blood supply. This was due to early and sustained caffeine-mediated vasoconstriction. That these vasoconstrictor properties are not limited to the periphery is evident from clinical reports of caffeine-mediated cerebral and coronary vasoconstriction. Additional physiological investigations of caffeine and the human cardiovascular system are needed.

\section{Conflicts of Interest}

The authors declare no conflicts of interest regarding the publication of this paper.

\section{References}

[1] Funk, G.D. (2009) Losing Sleep over the Caffeination of Prematurity. The Journal of Physiology, 587, 5299-5300. https://doi.org/10.1113/jphysiol.2009.182303

[2] Doyle, L.W., Ranganathan, S. and Cheong, J.L.Y. (2017) Neonatal Caffeine Treatment and Respiratory Function at Eleven Years in Children under 1,251 g at Birth. American Journal of Respiratory and Critical Care Medicine, 196, 1318-1324. https://doi.org/10.1164/rccm.201704-0767OC

[3] Doepker, C., Franke, K., Myers, E., Goldberger, J.J., Lieberman, H.R., O’Brien, C., Peck, J., Tenenbein, M., Weaver, C. and Wikoff, D. (2018) Key Findings and Implications of a recent systematic review of the potential adverse effects of caffeine consumption in Healthy Adults, Pregnant Women, Adolescents, and Children. $\mathrm{Nu}$ trients, 10, 1536-1552. https://doi.org/10.3390/nu10101536

[4] Voskoboinik, A., Koha, Y. and Kistler, P.M. (2018) Cardiovascular Effects of Caffeinated Beverages. Trends in Cardiovascular Medicine, in press. https://doi.org/10.1016/j.tcm.2018.09.019

[5] Cappelletti, S., Piacentino, D., Sani, G. and Aromatario, M. (2015) Caffeine: Cognitive and Physical Performance Enhancer or Psychoactive Drug? Current Neuropharmacology, 13, 71-88. https://doi.org/10.2174/1570159X13666141210215655

[6] Ferré, S. (2016) Mechanisms of the Psychostimulant Effects of Caffeine: Implications for Substance Use Disorders. Psychopharmacology, 233, 1963-1979. https://doi.org/10.1007/s00213-016-4212-2

[7] Grasser, E.K., Miles-Chan, J.L., Charrière, N., Loonam, C.R., Dulloo, A.G. and Montani, J.P. (2016) Energy Drinks and Their Impact on the Cardiovascular System: Potential Mechanisms. Advances in Nutrition, 7, 950-960. https://doi.org/10.3945/an.116.012526

[8] McLellan, T.M., Caldwell, J.A. and Lieberman, H.R. (2016) A Review of Caffeine's Effects on Cognitive, Physical and Occupational Performance. Neuroscience \& Biobehavioral Reviews, 71, 294-312. https://doi.org/10.1016/j.neubiorev.2016.09.001 
[9] Urry, E. and Landolt, H.P. (2015) Adenosine, Caffeine, and Performance: From Cognitive Neuroscience of Sleep to Sleep Pharmacogenetics. Sleep, Neuronal Plasticity and Brain Function, 25, 331-366. https://doi.org/10.1007/7854_2014_274

[10] Rivera-Oliver, M. and Díaz-Ríos, M. (2014) Using Caffeine and Other Adenosine Receptor Antagonists and Agonists as Therapeutic Tools against Neurodegenerative Diseases: A Review. Life Sciences, 101, 1-9. https://doi.org/10.1016/j.lfs.2014.01.083

[11] Boia, R., Ambrósio, A.F. and Santiago, A.R. (2016) Therapeutic Opportunities for Caffeine and $\mathrm{A}_{2 \mathrm{~A}}$ Receptor Antagonists in Retinal Diseases. Ophthalmic Research, 55, 212-218. https://doi.org/10.1159/000443893

[12] Ferré, S., Bonaventura, J., Tomasi, D., Navarro, G., Moreno, E., Cortés, A., Lluís, C., Casadó, V. and Volkow, N.D. (2016) Allosteric Mechanisms within the Adenosine $\mathrm{A}_{2 \mathrm{~A}}$-Dopamine $\mathrm{D}_{2}$ Receptor Heterotetramer. Neuropharmacology, 104, 154-160. https://doi.org/10.1016/j.neuropharm.2015.05.028

[13] Merrill, G.F. and Sharp, V.A. (2018) Undesirable Cardiovascular Effects of Hot Drinks. International Journal of Clinical and Medical Cases, 1, 117-124.

[14] Laskowski, L.K., Henesch, J.A., Nelson, L.S., Hoffman, R.S. and Smith, S.W. (2015) Start Me Up! Recurrent Ventricular Tachydysrhythmias Following Intentional Concentrated Caffeine Ingestion. Clinical Toxicology, 53, 830-833.

[15] Musgrave, I.F., Farrington, R.L., Hoban, C. and Byard, R.W. (2016) Caffeine Toxicity in Forensic Practice: Possible Effects and Under-Appreciated Sources. Forensic Science, Medicine, and Pathology, 12, 299-303. https://doi.org/10.1007/s12024-016-9786-9

[16] Jones, A.W. (2017) Review of Caffeine-Related Fatalities along with Postmortem Blood Concentrations in 51 Poisoning Deaths. Journal of Analytical Toxicology, 41, 167-172. https://doi.org/10.1093/jat/bkx011

[17] Wikoff, D., Welsh, B.T., Henderson, R., Brorby, G.P., Britt, J., Myers, E., Goldberger, J., Lieberman, H.R., O’Brien, C. and Peck, J., et al. (2017) Systematic Review of the Potential Adverse Effects of Caffeine Consumption in Healthy Adults, Pregnant Women, Adolescents, and Children. Food and Chemical Toxicology, 109, 585-648. https://doi.org/10.1016/j.fct.2017.04.002

[18] Gibbs, F.A., Gibbs, E.L. and Lennon, W.G. (1935) Cerebral Blood Flow in Man as Influenced by Adrenalin, Caffeine, Amyl Nitrite and Histamine. American Heart Journal, 10, 916-924. https://doi.org/10.1016/S0002-8703(35)90421-5

[19] Shenkin, H.A. (1951) Effects of Various Drugs upon Cerebral Circulation and Metabolism in Man. Journal of Applied Physiology, 3, 465-447. https://doi.org/10.1152/jappl.1951.3.8.465

[20] Scheinberg, P. and Jayne, H.W. (1952) Factors Influencing Cerebral Blood Flow and Metabolism. Circulation, 5, 225-226. https://doi.org/10.1161/01.CIR.5.2.225

[21] Moyer, J.H., Tashnek, A.B., Miller, S.J., Snyder, H. and Bowman, R.O. (1952) The Effect of Theophylline with Ethylenediamine (Aminophylline) and Caffeine on Cerebral Hemodynamics and Cerebrospinal Fluid Pressure in Patients with Hypertensive Headaches. The American Journal of the Medical Sciences, 224, 377-385.

[22] Mathew, R.J., Barr, D.L. and Weinman, M.L. (1983) Caffeine and Cerebral Blood Flow. The British Journal of Psychiatry, 143, 604-608. https://doi.org/10.1192/bjp.143.6.604

[23] Mathew, R.J. and Wilson, W.H. (1985) Caffeine-Induced Changes in Cerebral Circulation. Stroke, 16, 814-817. https://doi.org/10.1161/01.STR.16.5.814

[24] Merola, A., Germuska, M.A., Warnert, E.A., Richmond, L., Helme, D., Khot, S., 
Murphy, K., Rogers, P.J., Hall, J.E. and Wise, R.G. (2017) Mapping the Pharmacological Modulation of Brain Oxygen Metabolism: The Effects of Caffeine on Absolute $\mathrm{CMRO}_{2}$ Measured Using Dual Calibrated fMRI. Neuroimage, 155, 331-343.

[25] Folkow, B. (1971) Regulation of the Peripheral Circulation. British Heart Journal, 33, 127-131. https://doi.org/10.1136/hrt.33.Suppl.27

[26] Wollner, L., McCarthy, S.T., Soper, N.D. and Macy, D.J. (1979) Failure of Cerebral Autoregulation as a Cause of Brain Dysfunction in the Elderly. BMJ, 11, 117-118. https://doi.org/10.1136/bmj.1.6171.1117

[27] Steinhausen, M., Endlich, K. and Wiegman, D.L. (1990) Glomerular Blood Flow. Kidney International, 38, 769-784. https://doi.org/10.1038/ki.1990.271

[28] Goodwill, A.G., Dick, G.M., Kiel, A.M. and Tune, J.D. (2017) Regulation of Coronary Blood Flow. Comprehensive Physiology, 7, 321-382. https://doi.org/10.1002/cphy.c160016

[29] Goodson, C.M., Rosenblatt, K., Rivera-Lara, L., Nyquist, P. and Hogue, C.W. (2018) Cerebral Blood Flow Autoregulation in Sepsis for the Intensivist: Why Its Monitoring May Be the Future of Individualized Care. Journal of Intensive Care Medicine, 33, 63-73. https://doi.org/10.1177/0885066616673973

[30] Duncker, D.J., Koller, A., Merkus, D. and Canty Jr., J.M. (2015) Regulation of Coronary Blood Flow in Health and Ischemic Heart Disease. Progress in Cardiovascular Diseases, 57, 409-422. https://doi.org/10.1016/j.pcad.2014.12.002

[31] Beyer, A.M. and Gutterman, D.D. (2012) Regulation of the Human Coronary Microcirculation. Journal of Molecular and Cellular Cardiology, 52, 814-821. https://doi.org/10.1016/j.yjmcc.2011.10.003

[32] Mustafa, S.J., Morrison, R.R., Teng, B. and Pelleg, A. (2009) Adenosine Receptors and the Heart: Role in Regulation of Coronary Blood Flow and Cardiac Electrophysiology. In: Wilson, C., Mustafa, S., Eds., Adenosine Receptors in Health and Disease. Handbook of Experimental Pharmacology, Springer, Berlin, Heidelberg. https://doi.org/10.1007/978-3-540-89615-9_6

[33] Feigl, E.O. (1983) Coronary physiology. Physiological Reviews, 63, 1-205. https://doi.org/10.1152/physrev.1983.63.1.1

[34] Berne, R.M. (1964) Regulation of Coronary Blood Flow. Physiological Reviews, 44, 1-29. https://doi.org/10.1152/physrev.1964.44.1.1

[35] Olsson, R.A., Davis, C.J., Khouri, E.M. and Patterson, R.E. (1976) Evidence for an Adenosine Receptor on the Surface of Dog Coronary Myocytes. Circulation Research, 39, 93-98. https://doi.org/10.1161/01.RES.39.1.93

[36] Burnstock, G. (1980) Purinergic Receptors in the Heart. Circulation Research, 46, 175-182.

[37] Mustafa, S.J. (1980) Cellular and Molecular Mechanism(s) of Coronary Flow Regulation by Adenosine. Molecular and Cellular Biochemistry, 31, 67-87. https://doi.org/10.1007/BF00240813

[38] Dutta, P. and Mustafa, S.J. (1980) Binding of Adenosine to the Crude Plasma Membrane Fraction Isolated from Dog Coronary and Carotid Arteries. Journal of Pharmacology and Experimental Therapeutics, 214, 496-502.

[39] Dai, Q.-F., Wang, Y.-Y., Liu, Q., Xin, J.-J., Lu, F.-Y., Cui, J.-J., Wu, S.-Y., Zhou, C., Zhao, Y.-X., Gao, J.-H. and Yu, X.-C. (2018) Role of Adenosine A2B Receptor in Mediating Acupuncture Pretreatment-Induced Cardioprotection via Influencing Intracellular Calcium Regulators. Acupuncture Research, 43, 576-580.

[40] Rivkees, S.A. and Wendler, C.C. (2017) Long-Term Consequences of Disrupting 
Adenosine Signaling during Embryonic Development. Molecular Aspects of Medicine, 55, 110-117. https://doi.org/10.1016/j.mam.2017.02.001

[41] Esmaili, Z. and Heydari, A. (2018) Effect of Acute Caffeine Administration on PTZ-Induced Seizure Threshold in Mice: Involvement of Adenosine Receptors and NO-cGMP Signaling Pathway. Epilepsy Research, 149, 1-8. https://doi.org/10.1016/j.eplepsyres.2018.10.013

[42] Dos Santos, M.K.F., Gavioli, E.C., Rosa, L.S., de Paula Soares-Rachetti, V. and Lobão-Soares, B. (2018) Craving Espresso: The Dialetics in Classifying Caffeine as an Abuse Drug. Naunyn-Schmiedeberg's Archives of Pharmacology, 391, 1301-1318. https://doi.org/10.1007/s00210-018-1570-9

[43] Muñoz, M.D. and Solís, J.M. (2018) Characterization of the Mechanisms Underlying the Special Sensitivity of the $\mathrm{CA}_{2}$ Hippocampal Area to Adenosine Receptor Antagonists. Neuropharmacology, 144, 9-18. https://doi.org/10.1016/j.neuropharm.2018.10.017

[44] McCreedy, A., Bird, S., Brown, L.J.A., Shaw-Stewart, J.A. and Chen, Y.F. (2018) Effects of Maternal Caffeine Consumption on the Breastfed Child: A Systematic Review. Swiss Medical Weekly, 148, w14665. https://doi.org/10.4414/smw.2018.14665

[45] Leal, M., Barletta, M. and Carson, S. (1990) Maternal-Fetal Electrocardiographic Effects and Pharmacokinetics after an Acute IV Administration of Caffeine to the Pregnant Rat. Reproductive Toxicology, 4, 105-120.

https://doi.org/10.1016/0890-6238(90)90004-F 